\title{
Research on Human Resource Management from the Perspective of Competency
}

\author{
Pei Xu ${ }^{1, a}$, Ke Zhang ${ }^{1, b}$ \\ 'Beijing Normal University, Beijing 100875, China. \\ a381102168@qq.com, bzhangkebnu@163.com
}

\begin{abstract}
Human resources are the first driving force for the development of enterprises. The scientific human resource management mode helps to maintain the human resources advantages of enterprises. In the era of twenty-first Century, the traditional human resources management has exposed the problems of backward management concept, lagging management methods and poor management quality. How to promote the improvement of human resources management and guarantee the competitive advantage of human resources is a problem that business managers need to think about. The concept of competency provides new ideas and suggestions for the management of human resources, and from the analysis of the characteristics of the reform of human resource management at the present stage, the human resource management model based on the perspective of competency will certainly become the trend of the times. Based on competency perspective, this paper explores the human resource management mode of enterprises.
\end{abstract}

Keywords: Competency, enterprise human resource management, innovation strategy.

\section{Interpretation of Related Concepts Based on Competency}

\subsection{Basic Concepts of Competence}

The concept of competency is put forward by Professor David of Harvard University in 1973. It describes the outstanding characteristics of individuals in their work. In Professor David's view, competency is a distinguishing feature, which can distinguish the "outstanding" and "outstanding" from the ordinary people. Specifically, competency is a description of the individual's characteristics that can be quantified, evaluated and distinguished from others in such fields as attitudes, values, individual traits, and knowledge skills. For example, a person who works in the field of computer, performs a program compilation with other colleagues, which shows strong leadership in the work and can guide other participants to complete computer programming well. The ability to guide, organize, and coordinate in the process of program compilation is one of the characteristics of the person's competence, which is often less than that of other workers. With the deepening of the study of relevant competency characteristics, many scholars are more inclined to define competence from three important dimensions, which are professional dimension, behavior dimension and strategic dimension. Among them, the occupation dimension refers to the related skills of the individual dealing with the job and the daily business, and the behavior dimension is the ability to deal with the non job job and the ability to solve the problem in the face of the special circumstances; the strategic dimension evaluates the individual's management ability under the comprehensive environment.

\subsection{Interpretation of Three Characteristics of Competence}

According to the definition and practice of competency, we can describe the characteristics of competency from three aspects. The first is the individual character. In short, individual characteristics describe what individuals can do in their careers and what jobs they are competent for. Individual characteristics are a comprehensive reflection of the attributes possessed by an individual. It is a trait accumulated in the process of long-term learning and development. Individual characteristics mainly include individual knowledge, skills, emotional attitudes, values and so on. Second is the behavior characteristic of the individual. Simply define the behavior characteristics of individuals: what do they understand to do. Compared to the individual characteristics, the behavior features more emphasis on the application of the individual to the skills, that is, in a specific environment, what kind of thinking and values will be used to analyze the problem, and how to use 
the knowledge and skills of self learning to solve the problem. The third is the feature of the situation. Competence is not an empty theoretical description. It is an individual trait reflected in specific situations. Through the study of scholars, it is found that the competence characteristics of different positions, different working environments and different cultural environments often show great differences. Therefore, when applying competency theory in the management of human resources, it is necessary to apply this theory to the framework of "individual job organization". Scholars define the corresponding competency model for different occupations, and competency model comprehensively depicts the relevant competency that an individual should possess. Take the "customer supervisor" as an example, the competency it should possess is as follows:

Table 1. The competence of the customer manager

\begin{tabular}{ccc}
\hline Modular & Competence & dimension \\
\hline Self management & Achievement orientation and learning & Self vision \\
Employee & innovation & pursuit of excellence \\
management & Team management & team work and subordinates \\
Task & Customer orientation and planning & Mining demand and effective \\
implementation & management & response \\
\hline
\end{tabular}

\section{Human Resource Management Strategy Based on Competency Perspective}

Human resources management includes human resources planning, staff training, performance appraisal, salary management and other factors. Human resource management based on the perspective of competency is to integrate the competence theory in human resource planning, staff training, performance assessment and salary management.

\subsection{Competence Analysis from the Perspective of Competence}

The job analysis based on the competency perspective is to use the theory and method of competency to compare the competence characteristics of the excellent workers and the ordinary workers, and then to plan the personal position of the staff more scientifically. This is mainly followed by several steps. First, setting up a post target and performance evaluation system. Second, interviews are conducted on employees. Interview forms are mainly event interviews to allow employees to describe an excellent project (which needs to be prepared for interviews and samples before this). Third, we analyze and verify the results of the event interview, and let the staff operate on a given project. Fourth, according to the results of project validation, we should identify excellent employees and ordinary employees as the basis for job placement.

\subsection{Staff Selection and Training from the Perspective of Competency}

Employee selection and training is an important measure to protect the excellent human resources reserves of enterprises, and the use of competency theory helps to better achieve this task. The traditional methods of selecting and training employees are inclined to the explicit characteristics of knowledge and skills, such as the employees' knowledge and skills. This way is unavoidable, and it is difficult to "optimize and transform" the staff in essence. Applying competency theory to staff selection and training can find problems and solve problems in a more comprehensive and in-depth way. Besides paying attention to the knowledge and skills of the staff, the theory of competency also attaches great importance to the employees' feelings, attitudes and values. In a sense, the knowledge and skills can be improved through a period of training, while the emotion, attitude and values are difficult to change in the short term and use the theory of competency. It is very important for the development of enterprises to select employees with correct attitude and correct values. While the staff training, according to the competency theory, we can quantify the shortcomings of the staff in some aspects and carry out training to improve the overall quality of the staff. 


\subsection{Salary Management from The Perspective of Competency}

The significance of salary management in human resource management is more and more valued by managers. Excellent managers not only give employees a sense of corporate collective and honor, but also pay attention to material incentives for employees. Salary management plays an important role in human resource management as an incentive measure. Using competency theory for staff management can scientifically and effectively assign the salaries of employees, and achieve "Noja do Law, labor and more people". Through the analysis of the staff's competence characteristics, the employees' outstanding skills and contributions in a certain field are found, and then the salary of the employees is determined reasonably, and the differential management of the salary of the employees in different positions is realized. Employee compensation management based on competency perspective has two important meanings. First, it helps to form the core competence of enterprises. Managers use competency theory to comprehensively analyze the characteristics of each employee, which helps employees to develop a clearer understanding of themselves, take the initiative to make up their own strengths, and improve their comprehensive quality through continuous learning and experience. In the long run, this is a common practice and contributes to the formation of core competence and excellent culture. Second, it helps enterprises retain and absorb a large number of high-quality talents. Employees' salary management from the perspective of competency has abandoned the traditional "official standard" thought. Employees need not improve their salary in seeking the promotion of administrative positions. Employees can learn knowledge and skills and improve their professional ability to get higher salary. This has effectively promoted the vertical development of employees, and also helped the enterprises. Strengthen the comprehensive competitiveness of itself.

\section{Summary}

In conclusion, the application of competency theory in human resource management helps to improve the quality of human resource management. The characteristics of competency mainly include individual characteristics, behavior characteristics and situational characteristics. Human resource management based on competency perspective should integrate competency theory in the aspects of staff appointment, selection, training, salary management and so on, in order to promote the promotion of the quality of human resource management.

\section{References}

[1]. Luo Hao Jie. Research on human resource management system from the perspective of competency model [J]. Chinese business theory, 2018 (7).

[2]. Fang Yong Lei. Competency based human resource management model [D]. Northeastern University, 2005.

[3]. Yin Qiang. Innovation of human resource management system based on competency [J]. Chinese Journal, 2012 (7).

[4]. Ma Hongrong, Wu Rong. Competency based human resource management mode [J]. China business (second half month), 2010 (8): 283.

[5]. Sun Zhongmin. Human resource management system innovation based on competency [J]. Management scientist, 2012 (24). 